\title{
WAYFINDING EM APLICATIVOS DE RECOMENDAÇÃO DE ROTA: COERÊNCIA COM MAPAS COGNITIVOS
}

\section{WAYFINDING IN ROUTE RECOMMENDATION OF APPS: CONSISTENCY WITH COGNITIVE MAPS}

\author{
SILVA, João Batista da (1); \\ SOUZA, Charles Bamam Medeiros de (2); \\ KAFENSZTOK, Marcia (3); \\ ROSA, José Guilherme Santa (4) \\ PINHO, Andre Luis Santos de (5) \\ (1) (2) (3) UFRN, alunos do Mestrado Profissional em Design \\ Email: joobsi@hotmail.com \\ Email: charlesbamam@gmail.com \\ Email: $\underline{\text { mkdesign@terra.com.br }}$ \\ (4) (5) UFRN, Professores Doutores do Mestrado Profissional em Design \\ Email: jguilhermesantarosa@gmail.com \\ Email: pinho@ccet.ufrn.br
}

\begin{abstract}
RESUMO
Este artigo apresenta uma avaliaçao dos aplicativos de recomendação de rota do Google Maps e Waze, verificando a coerência desses com os mapas cognitivos dos usuários por meio de comparação entre as rotas utilizadas pelos usuários e as rotas sugeridas pelos aplicativos, tomando como referência os princípios de Wayfinding e a ocorrência dos elementos de Lynch: vias, pontos nodais e marcos.
\end{abstract}

Palavras-chave: Wayfinding, Mapas Cognitivos, Aplicativos, Geolocalização.

\begin{abstract}
This article presents an assessment of Google Maps and Waze route recommendation applications, checking the consistency of those, with cognitive user's maps, through comparison among routes used by users and the routes suggested by these applications, with reference to the principles of Wayfinding and the incidence of Lynch elements: routes, nodes and landmarks.
\end{abstract}

Keywords: Wayfinding, cognitive maps, apps, geolocation. 


\section{INTRODUÇÃO}

A cada dia a tecnologia está mais presente em nossas vidas. Ela tem nos acompanhado diariamente através do uso constante dos smartphones, aparelhos portáteis e individuais, participante da vida dos usuários em casa, no trabalho ou em qualquer outro local. $\mathrm{O}$ usuário de smartphone, que vive na cidade, sofre muitos impactos que interferem no seu deslocamento, no ir e vir e na maneira como encontram seus destinos, em meio a tanta interferência arquitetônica. Torna-se portanto necessário, além de identificar um local, orientar pessoas em um ambiente, ajudando-as a o percorrerem (SCARIOT, 2013, p. 13). A geolocalização a serviço da cognição, tornou-se um facilitador da vida nas cidades, tendo em vista inclusive a necessidade de se locomover com rapidez e segurança, dentro dos grandes centros urbanos.

Tendo em vista essa problemática, Scariot define o Wayfinding (sem tradução para a língua portuguesa) como sendo "conjuntos de artefatos gráficos (e.g., placas, totens, mapas) que têm como função dar suporte ao deslocamento e orientação em local aberto ou no interior de ambiente construído, visando à utilização adequada de serviços" (SCARIOT, 2013, p. 18). Diz respeito, portanto, a se locomover ao longo de um percurso e realizar os processos mentais envolvidos nessa tarefa. Esse processo cognitivo ocorre em três etapas: o tratamento da informação, a tomada da decisão e a execução da decisão (ANDRADE e BINS ELY, 2014).

Este tipo de sistema, quando bem projetado, não só unifica visualmente um local, mas também auxilia o entendimento e utilização deste. Calori (2007, apud SCARIOT, 2013, p. 13) ressalta que esta interação afeta a sensação de bem-estar, segurança e tranquilidade do usuário quando em um local não familiar - o que geralmente está atrelado a um elevado grau de tensão. Quando a comunicação do ambiente é feita de forma inadequada, a experiência do usuário em relação a este ambiente será negativa. Em locais como aeroportos, hospitais e centros urbanos, as corretas orientações de percurso, são primordiais para o conforto dos usuários.

É essencial levar em consideração o modelo mental que os usuários fazem ao se locomoverem. Cada pessoa gera um caminho quando se projeta indo a determinado ponto. Conforme argumenta Norman (1998), por exemplo, conhecer o modelo mental que o usuário cria acerca do sistema que será desenvolvido, ou de sistemas similares, é a forma mais eficaz de aproximar o modelo conceitual do designer ao modelo mental do usuário, a assim projetar corretamento um.

Muitos aplicativos de recomendação de rotas se propõem a resolver esta questão, oferecendo geolocalização e sugestão de rotas. São cada vez mais utilizados no dia a dia das grandes cidades, favorecendo a fácil localização no trânsito. Pretendemos abordar apenas os aplicativos mais populares, quais sejam, Waze ${ }^{1}$ e Google Maps ${ }^{2}$, por considerarmos o acesso a estes mais frequentes.

A perspectiva do presente artigo pretende dar ênfase não somente a aspectos de eficácia e eficiência na realização da tarefa, mas também direciona a atenção quanto à experiência do usuário ao entrar em contato com o sistema de informação, uma vez que a literatura indica uma discrepância entre as medições avaliativas objetivas e as subjetivas (HAN et al., 2000; HASSENZAHL e TRACTINSKY, 2006; HORNBACK, 2006 apud SCARIOT, 2013, p. 14).

1 Aplicativo de geolocalização disponível pelo sítio https://www.Waze.com/pt-BR e nas lojas de aplicativos GooglePlay e AppleStore.

2 Aplicativo de geolocalização disponível pelo sítio https://www.google.com.br/maps e nas lojas de aplicativos GooglePlay e AppleStore. 


\section{WAYFINDING}

Orientar-se, locomover-se e encontrar-se nos espaços e chegar a destinos de maneira mais eficaz e eficiente possível é a preocupação mater do Wayfinding.

O processo de wayfinding compreende, portanto, todos os processos perceptuais, cognitivos e comportamentais envolvidos na busca de um destino desejado em um espaço (ARTHUR e PASSINI, 2002 apud SCARIOT, 2013, p. 18).

Por se tratar de um método de design, é importante salientar que métodos avaliativos para Sistemas de Informação para Wayfinding (SIW) encontram-se, em geral, descritos junto aos processos de design centrado no usuário, no entanto, sua maioria tem ênfase nas relações objetivas entre usuário e interface, o que sugere que as relações subjetivas estejam sendo negligenciadas, possivelmente por não serem de fácil acesso, medição e interpretação (SCARIOT, 2013, p. 14).

Esse pensamento é compartilhado por Lynch (1997), que acredita que orientação não é produto de um "instinto", e sim da interpretação pelo indivíduo de estímulos recebidos do ambiente externo. Destarte, pensar Wayfinding é pensar num design centrado no usuário, em suas limitações, desejos, requisitos e como oferecer a este a solução cabível e ajustada a sua necessidade de localização. Para o desenvolvimento de uma solução baseada em Wayfinding deve-se levar em conta três aspectos

(a) a tomada de decisão, referente ao planejamento das ações; (b) a execução da decisão, que é a transformação do plano em ações, e (c) o processamento da informação, que corresponde à percepção do ambiente e a transformação das informações em imagem ambiental. Considerar tais aspectos é requisito primordial para um projeto bem elaborado e executado, tendo em vista a imensa gama de decisões baseadas na cultura de locomoção / orientação do usuário em relação aos espaços (ARTHUR E PASSINI, 2002 apud SCARIOT, 2013, p. 19).

Satalich (1995, apud SCARIOT, 2013, p. 19) descreve quatro passos do processo de wayfinding de um usuário:

1. Orientação: o usuário deve reconhecer sua localização em relação aos objetos vizinhos e o local/meta onde deseja chegar; 2. Decisão da rota: deve selecionar uma rota que conduza ao local da meta; 3. Monitoramento da rota: deve monitorar a rota selecionada para conferir se ela está levando ao objetivo esperado; 4. Reconhecimento do destino: deve reconhecer que chegou (ou está bem próximo) ao local desejado.

Padovani e Moura (2008) descrevem que, na prática, quando um indivíduo tenta se orientar em algum ambiente, ele explora e observa as sinalizações, rotas visíveis, consulta mapas, solicita informações a transeuntes e outras fontes de informação que estejam disponíveis. Então, ele analisa as informações recém-coletadas, gera e compara alternativas de solução para o problema, escolhe o melhor caminho e aplica esse conhecimento realizando a tarefa motora de dirigir-se ao local inicialmente desejado. 
Scariot (2013, p. 72) identificou alguns princípios que tornam espaços efetivamente navegáveis, destacando três critérios principais que podem servir como base geral para a avaliação de Sistemas de Informação para Wayfinding (SIW):

a. Primeiro, se um usuário consegue descobrir ou inferir sua localização atual, avaliar se um usuário consegue responder questões como: "onde estou?" e "qual caminho estou escolhendo?", tanto verbalmente quanto indicando através de desenhos;

b. Segundo, se uma rota ou destino podem ser encontrados, avaliar a capacidade de se realizar tarefas de wayfinding, o que ocorre quando o SIW permite que decisões acertadas sejam tomadas. Pode-se avaliar, por exemplo, se o usuário decide continuar na rota em que está ou prefere retornar ao ponto inicial, ou mesmo parar e coletar novas informações para confirmar a rota;

c. Terceiro, quão facilmente um usuário consegue acumular experiência de wayfinding no ambiente, engloba a imaginabilidade de um espaço de larga escala, ou seja, a capacidade de um usuário formar imagens mentais ou mapas coerentes desse ambiente.

Portanto, utilizar critérios de design centrado no usuário faz do Wayfinding uma estratégia essencial para facilitar a orientação das pessoas em condições cada vez mais precárias de locomoção, tendo em vista o crescimento das cidades, da quantidade de veículos, construção de barreiras e ainda, cansaço mental e quantidade de informação a que cada pessoa se depara no seu cotidiano.

Uma solução de Wayfinding que realmente considera o usuário centra seu projeto nele, deverá considerar o que este projeta em sua mente quando pretende deslocar-se em ambientes, sejam externos ou internos, carentes de sinalizações adequadas.

\section{MAPAS COGNITIVOS E OS ELEMENTOS DE LYNCH}

Localizar-se e locomover-se nas cidades, a partir do pressuposto de estar dirigindo um veículo automotivo, tem se tornado uma verdadeira odisséia. Daí a popularização inevitável dos aplicativos de recomendação de rota, assunto que será abordado no próximo capítulo deste artigo. Construir uma solução de orientação mental é crucial para os motoristas, eles fazem isso naturalmente através de um mapa cognitivo, que é análogo ao layout físico de um ambiente, indicando rotas, caminhos e relações entre os locais (GILLNER e MALLOT, 1998 apud PADOVANI e MOURA, 2008). Os usuários tem a capacidade de entender rotas e atalhos que o ajudam a locomover-se, deslocar-se nos ambientes, e fazem isso através do mapa cognitivo.

Segundo Scariot (2013, p. 23) a aquisição de conhecimento espacial resulta da junção dos processos de wayfinding e do mapeamento cognitivo, onde esta aquisição de informações sobre o ambiente (estágio de percepção) leva o usuário a se localizar e monitorar sua rota (estágio de avaliação/decisão e seleção de respostas), os quais resultam na movimentação pretendida (estágio de produção de respostas).

O usuário, deste modo, apreende, adquire conhecimento espacial através da formação de mapas mentais a respeito dos ambientes por onde deverá percorrer, a partir de tarefas (ir do ponto $A$ ao $B$, por exemplo), não sendo possível nem prático conforme Scariot (2013, p. 24) considerar a tarefa, o ambiente e o usuário como sendo partes separadas.

Reconhecido como um dos maiores autores sobre urbanismo, Kevin Lynch é responsável por uma das obras mais famosas e mais influentes dessa área do conhecimento: A Imagem da Cidade, onde destaca a maneira como percebemos a cidade e as suas partes constituintes, baseado em um extenso estudo em três cidades norte-americanas (Boston, Jersey City e Los Angeles), no qual pessoas eram questionadas sobre sua percepção da 
cidade, como estruturavam a imagem que tinham dela e como se localizavam. A partir desse estudo, Lynch classificou cinco elementos da imagem urbana, utilizados pelas pessoas como elementos distintivos para referências de rota, sendo eles: vias, pontos nodais e marcos, os principais, complementados por limites e bairros. Estes elementos não existem isoladamente, eles se sobrepõem e interligam-se constantemente ( $\mathrm{LYNCH}, 1997)$.

\section{APLICATIVOS DE RECOMENDAÇÃO DE ROTA}

Com a popularização dos smartphones e suas numerosas funcionalidades, que auxiliam os usuários em várias tarefas rotineiras, houve uma mudança considerável na forma como as pessoas buscam informação sobre seus destinos de deslocamento.

A tecnologia GPS (Global Position System) possibilita e facilita a pesquisa de geolocalizações, permitindo consultas online à rotas e destinos requeridos, e, em tempo real, orienta o deslocamentos dos usuários.

Os aplicativos de recomendação de rota mais conhecidos atualmente são o Google Maps e o Waze. O Google Maps tem versão mobile e Web, inclui visualização da rota, distância e tempo de percurso em alguns modais (carro, ônibus, pedestre e, em algumas localidades, bicicleta), além de recomendações de rotas. Já o Waze, também nas versões Web e mobile, funciona como um misto de geolocalizador e mídia social, já que ele permite que os usuários colaborem com a atualização das informações, interagindo com outros usuários, em tempo real, registrando as condições de transito, acidentes, etc. (CASTRO, 2014).

\section{METODOLOGIA}

Adotou-se como metodologia para coleta de dados uma entrevista com preenchimento de questionário que continha perguntas abertas e fechadas, gravação de descrição verbal de rota e posterior traçado de rota em mapa.

A população amostrada compreendeu motoristas profissionais ou não que conheciam a cidade do Natal, capital do estado do Rio Grande do Norte.

A amostra foi composta por 15 condutores de carros de passeio, desses 5 eram motoristas profissionais (homens) e 10 não profissionais. Dentre os não profissionais 5 eram mulheres e 5 eram homens.

Segundo Reis (2010, p. 49), as diferenças individuais devem ser consideradas e podem ser divididas em: idade; diferenças entre gêneros; fatores cognitivos e experiência em direção e navegação. Daí terem sido escolhidos três grupos distintos para a pesquisa, pois cada grupo contribuiu com suas diferenças e semelhanças no comportamento navegacional.

As perguntas da entrevista foram submetidas a um teste piloto com um motorista profissional, conforme recomenda Lakatos (2003, p. 203), para evitar falhas, ambiguidades ou inconsistência das questões.

A entrevista gravada correspondia a uma única pergunta, a saber: Qual o percurso que você faria para se deslocar do Shopping Via Direta até o Corpo de Bombeiros localizado na Av. Alexandrino de Alencar? A intenção era observar quais referências seriam usadas para identificar o percurso. As respostas foram gravadas e transcritas para uma planilha, os dados foram tratados, identificando-se as frequências de repetição das palavras que os entrevistados utilizaram para se orientar. 
Os pontos de partida (Shopping Via Direta) e chegada (Corpo de Bombeiros) foram escolhidos, primeiramente, por serem pontos conhecidos da cidade e, também, por possibilitarem uma variedade de rotas já que permite acessar ou não o Viaduto do $4^{\circ}$ centenário.

Após a entrevista, foi solicitado a cada sujeito que desenhasse num mapa, onde estavam identificados os pontos inicial (A) e final (B), o mesmo percurso que ele havia descrito na gravação. Segundo Alm (1990, apud REIS, 2010, p. 39), ao realizar dois estudos, o método de descrição verbal (por escrito) e o método de esboço cartográfico, um em sequência do outro, verifica-se a existência de resultados comuns nos estudos.

\section{RESULTADOS E DISCUSSÕES}

\subsection{Descrições verbais}

As rotas verbalizadas foram gravadas e posteriormente transcritas com auxílio do aplicativo Voice Note II do Google Chrome. No texto resultante foram verificadas as frequências de ocorrência das palavras e, as mais citadas estão relatadas no decorrer desse trabalho.

Os motoristas descreveram verbalmente o percurso e posteriormente o traçaram no mapa. Obteve-se um total de cinco rotas. As mais utilizadas foram: a rota que segue direto pela Avenida Salgado Filho e Avenida Alexandrino de Alencar, utilizadas por $40 \%$ dos motoristas, e a rota passando pela Avenida Salgado Filho, Avenida Prudente de Morais e Avenida Alexandrino de Alencar), utilizada por 33\% dos motoristas. Essas rotas percorrem as avenidas mais importantes da cidade e mais citadas pelos entrevistados em suas descrições.

A avenida Senador Salgado Filho é a continuidade da rodovia BR-101, dessa forma podemos dizer que ela foi citada por $100 \%$ dos entrevistados, pois nove citaram a palavra Salgado Filho e oito a BR-101, desses, três tinham citado a Salgado Filho e, excluindo-os, contabilizamos apenas mais cinco. A décima quinta ocorrência foi a citação isolada da marginal da BR-101.

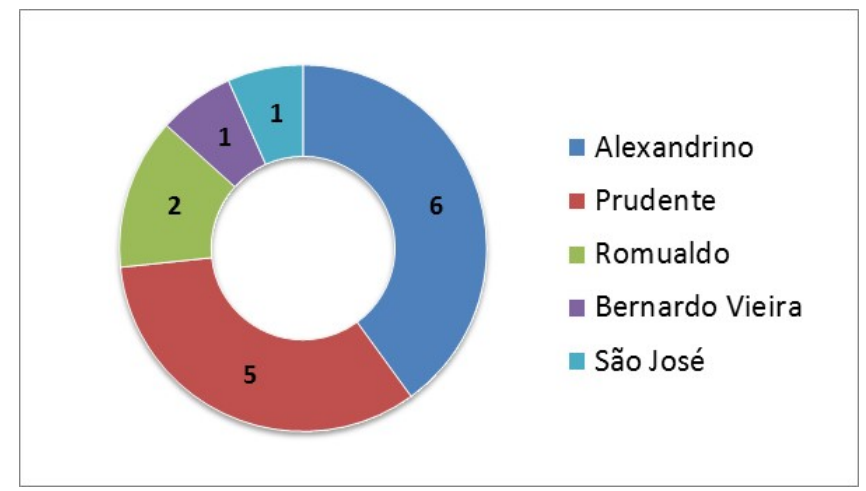

Gráfico 1 - Rotas descritas e traçadas pelos entrevistados.

A avenida Alexandrino de Alencar também foi citada por $100 \%$ dos motoristas já que foi informada como ponto de destino aos entrevistados.

A avenida Prudente de Morais foi citada por sete entrevistados em suas descrições, duas citações devidas a necessidade de informar que indo pela Alexandrino de Alencar o Corpo de Bombeiros fica "depois do sinal da Prudente de Morais". 


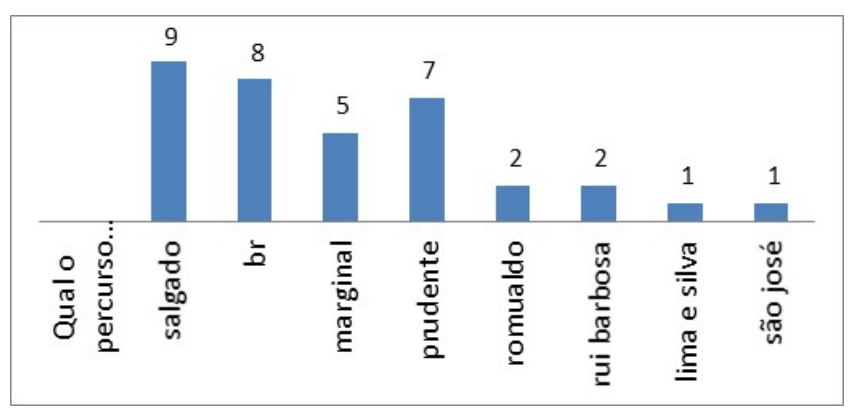

Gráfico 2 - Vias citadas pelos motoristas nas descrições verbais.

Além das vias, os pontos nodais e os marcos também foram citados pelos entrevistados, o que reforça a importância desses elementos urbanos perceptíveis que formam a imagem da cidade (LYNCH, 1997).

O retorno foi o ponto nodal citado por $100 \%$ dos entrevistados, esse local de interrupção do fluxo do trânsito tem uma enorme importância para o observador da cidade uma vez que se devem tomar decisões (LYNCH, 1997).

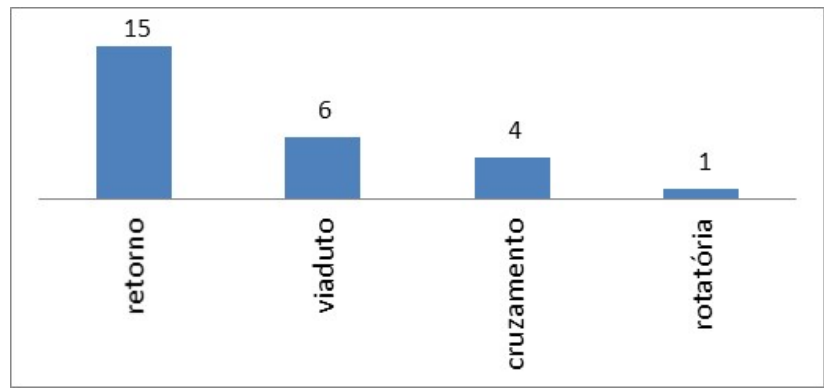

Gráfico 3 - Pontos nodais citados pelos motoristas nas descrições verbais.

Os marcos foram descritos por cinco entrevistados, o que corresponde a $33 \%$, sendo que dois deles utilizaram pelo menos três marcos em seus mapas cognitivos. O marco mais citado foi o sinal de trânsito ou semáforo, seguido pelo estádio de futebol (Arena das Dunas) e pelo Shopping Midway.

Os entrevistados que mais se utilizaram de marcos em suas descrições declararam ter muito conhecimento dos bairros percorridos ao longo da rota desenhada, ou seja, os mais familiarizados com a cidade tendem a confiar mais, como guias, nos sistemas de marcos (LYNCH, 1997).

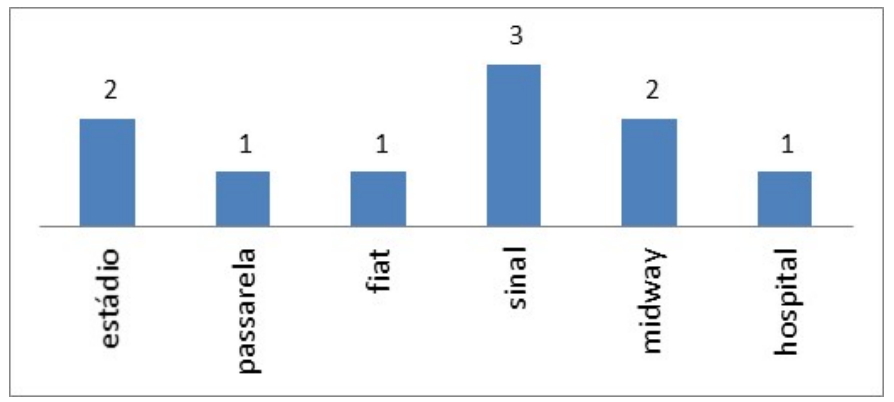




\section{Gráfico 4 - Marcos mais citados pelos motoristas nas descrições verbais.}

Ao serem questionados sobre o tipo de informação que mais utilizam para se orientar quando está procurando um local desconhecido, os motoristas entrevistados revelaram utilizar a tecnologia GPS (Global Position System), embutida nos aplicativos Google Maps e Waze também citados, o que juntos correspondem a $46 \%$ do total de entrevistados. Mas velhos hábitos como leitura de placas e perguntar a outras pessoas não foram descartados e correspondem à resposta de $40 \%$ dos motoristas. Os pontos de referência também foram citados e, segundo Burnett (1998, apud REIS, 2010 pg. 32) os motoristas se sentem confiantes e seguros em manter-se na rota quando as representações de auxílio à navegação apresentam pontos de referência.

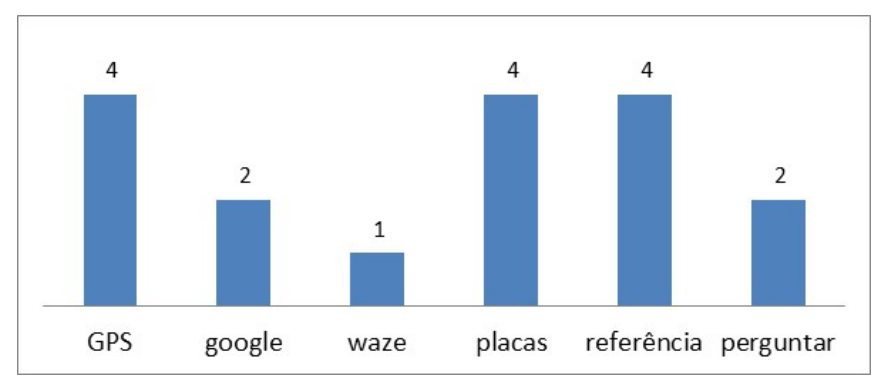

Gráfico 5 - Tipo de informação utilizada quando os motoristas procuram um local desconhecido.

\subsection{Rotas dos entrevistados}

As rotas que os entrevistados desenharam no mapa fornecido foram devidamente redesenhadas através da versão web do Google Maps, o que possibilitou mensurar a extensão de cada rota, em quilômetros.

O desenho da rota, combinado com as respostas do questionário permitiu várias inferências apoiadas em valores estatísticos.

No diagrama de dispersão entre a extensão da rota (eixo $x$ ) e o tempo que o entrevistado declarou que dirige (eixo y) há uma associação linear moderada, comprovada pelo coeficiente de correlação $r=-0,43$ (excluindo-se o ponto atípico, correspondente à unidade amostral $N^{0}$ 8). Essa correlação nos induz a concluir que quanto maior a experiência dos motoristas, menor a rota traçada.

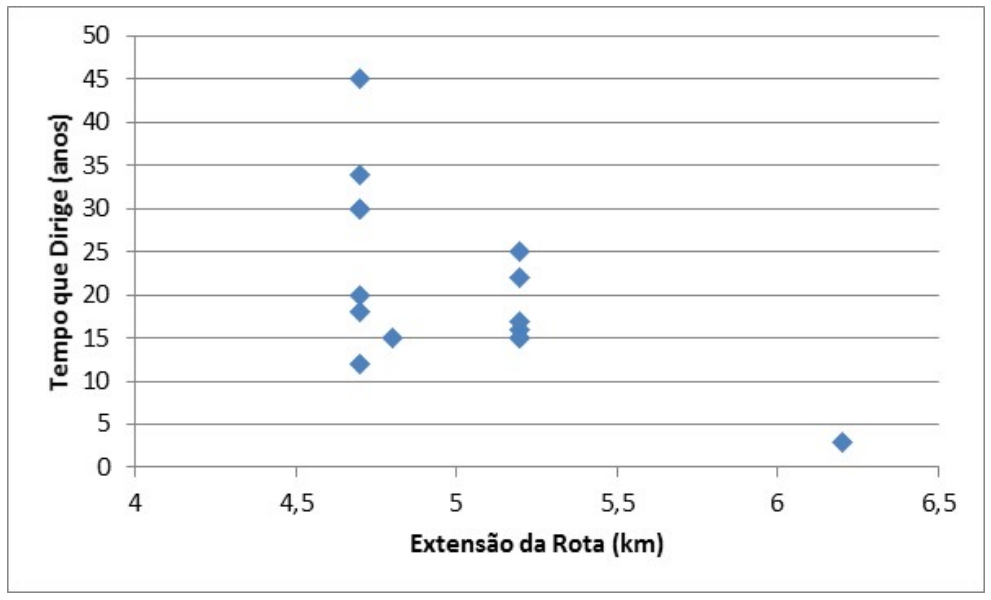

Gráfico 6 - Extensão da rota x tempo que dirige.

As extensões das rotas traçadas pelos entrevistados apresentaram uma moda, ou maior repetição, igual a $4,7 \mathrm{~km}$, o que se deve ao fato das rotas pela Prudente de Morais e pela 
Romualdo terem a mesma extensão. A mediana, com valor igual a 4,8km, está bem próxima da moda.

A extensão média das rotas foi de 5,01 km, o desvio padrão 0,41 e a variância 0,1678.

Comparando as extensões com as variáveis gênero e profissão, percebemos que as diferenças não são significativas, desprezando-se a u.a. № 8 cujo valor $6,2 \mathrm{~km}$ extrapola 0 intervalo definido pela média e pelo desvio padrão (4,6 a 5,42km).

Ao analisarmos o conhecimento dos participantes a respeito dos bairros aos quais 0 percurso está inserido, verificamos que a u.a. $N^{0} 8$ tinha pouco conhecimento sobre os bairros, o que justifica o fato dessa entrevistada ter traçado a maior rota de todas.

\subsection{ROTAS DOS APLICATIVOS}

A avaliação dos aplicativos Google Maps e Waze consistiu em avaliar as rotas geradas a partir do shopping Via Direta até o Corpo e Bombeiros. As rotas foram geradas e percorridas no domingo, 30 de novembro de 2014. Foram avaliados os aspectos relacionados à geração da rota inicial, incluindo número de rotas sugeridas, os dados de navegação por voz e texto e os elementos exibidos no mapa.

O smartphone utilizado foi um modelo com sistema operacional Android 4.4, GPS, tela touch screen de 4,5", processador Quad Core 1,2GHz e 16MB de memória interna.

\subsubsection{Google Maps}

No Google Maps foram retornadas três rotas, sendo que a primeira, pela Nascimento de Castro e Rui Barbosa, não coincide com as rotas traçadas pelos entrevistados. Isso pode ser explicado pelo fato dessa rota orientar uma conversão proibida à esquerda, no cruzamento da avenida Nascimento de Castro com a Rui Barbosa, o que demonstra um maior conhecimento da cidade por parte dos motoristas.

Quanto à descrição das vias, as rotas sugeridas não diferenciam a pista principal da BR-101 (Salgado Filho) da pista marginal, lembrando que a marginal foi citada por cinco entrevistados (33\%) em seus mapas mentais.

Na navegação por texto e voz apenas o ponto nodal retorno foi informado pelo aplicativo. Os demais pontos nodais viaduto e cruzamento, presentes nas rotas coincidentes entre aplicativo e entrevistados, não foram informados.

$\mathrm{Na}$ segunda rota sugerida pelo aplicativo, a rota pela Prudente de Morais, a informação sobre o viaduto é crucial para a correta tomada de decisão e, nesse caso, o Google Maps não alerta o motorista que ele tem que subir ou "pegar" o viaduto como foi alertado por $80 \%$ dos motoristas que escolheram essa rota no seu mapa mental.

Os marcos, pontos de referência considerados externos ao observador ( $\mathrm{LYNCH}, 1997$ p. 88) não foram informados na navegação por texto e voz do aplicativo. Porém, alguns dos marcos presentes no mapa mental dos entrevistados (estádio, Midway e hospital) são exibidos no mapa do aplicativo, mas não são destacados ao longo da navegação e, dessa forma, passam despercebidos. 


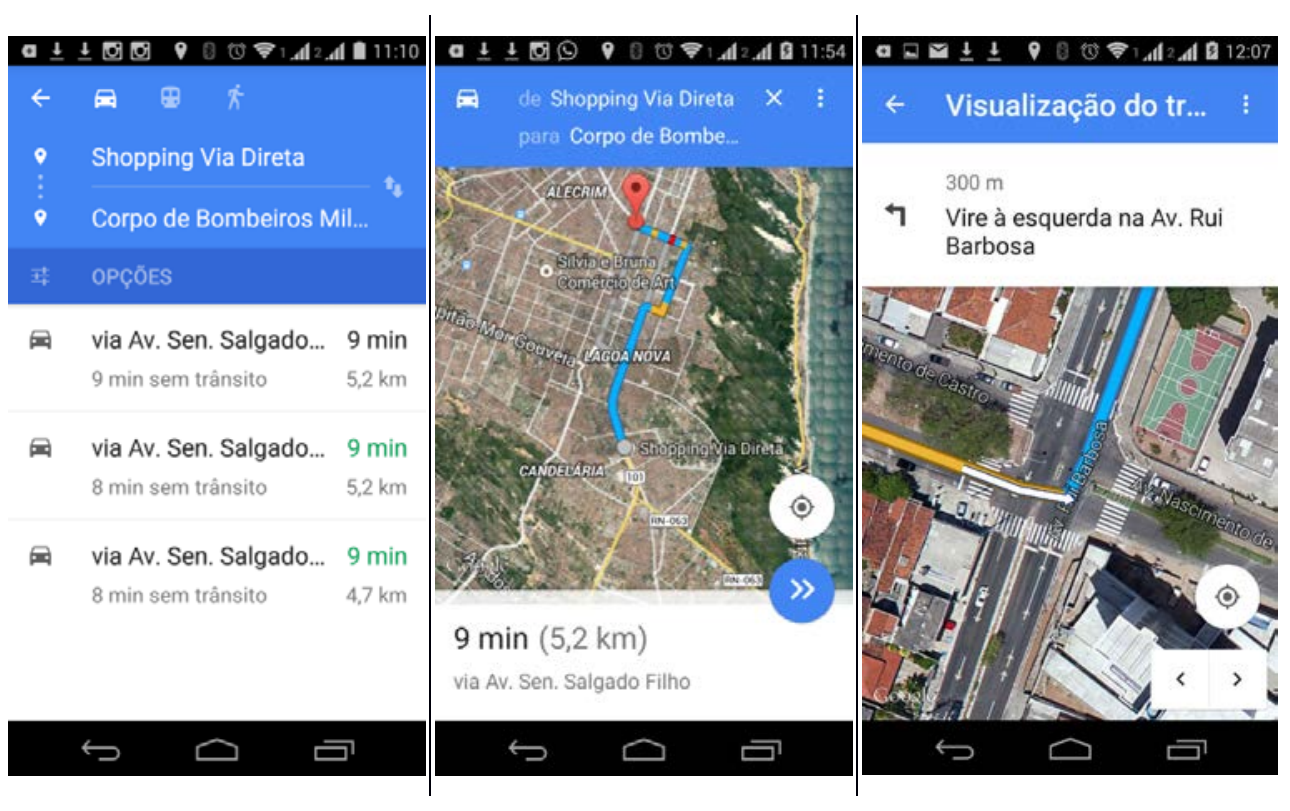

Figura 1 - Rotas sugeridas pelo Google Maps e conversão proibida.

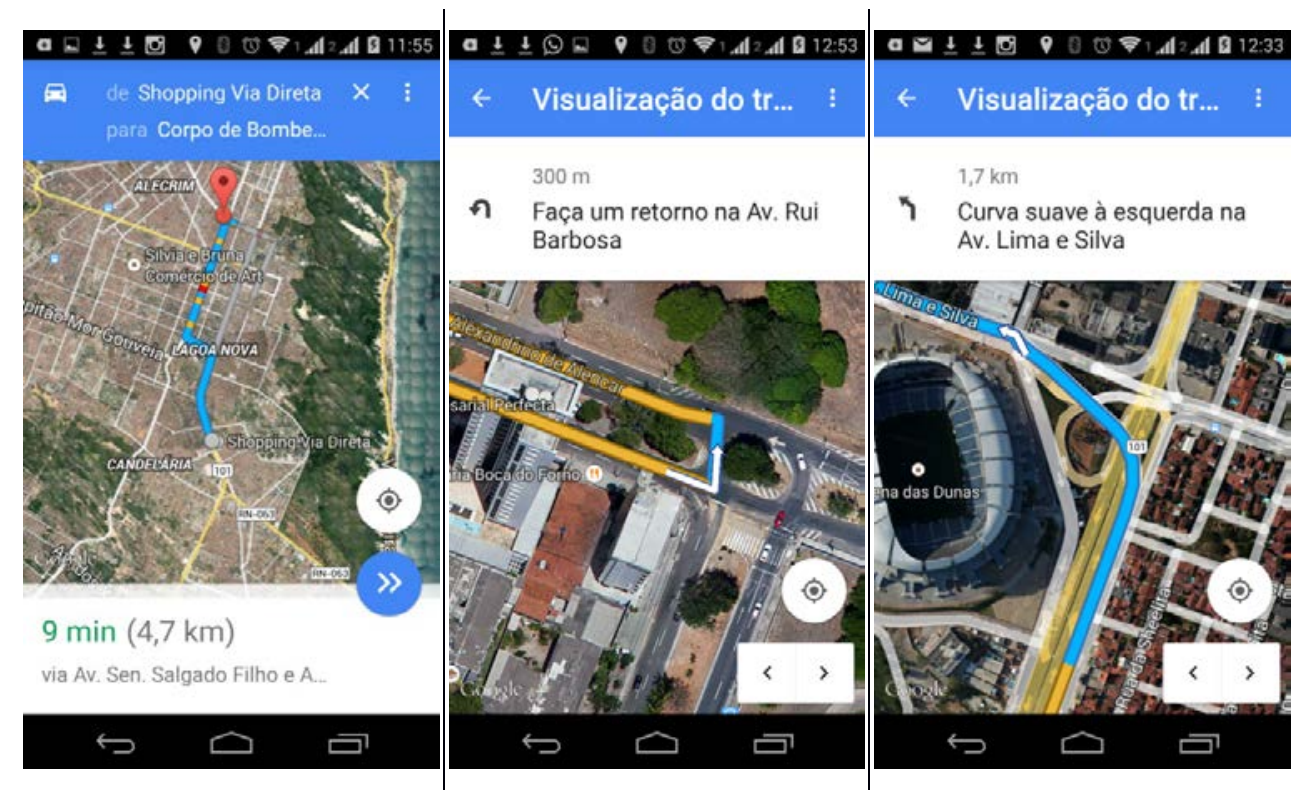

Figura 2 - Ponto nodal informado (retorno) e não informado (viaduto).

\subsubsection{Waze}

No Waze, foram retornadas apenas duas rotas. A primeira, pela Prudente de Morais e a segunda pela Romualdo Galvão. 

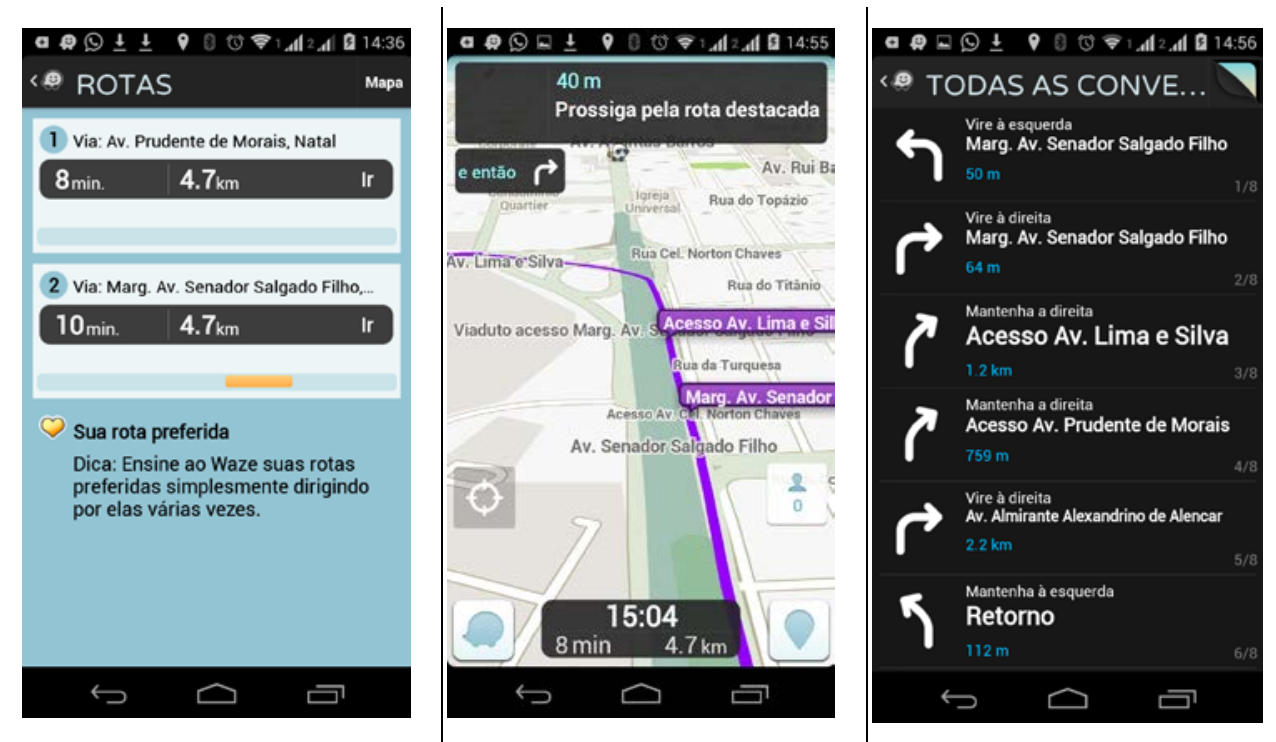

Figura 3 - Rotas sugeridas pelo Waze e orientação com seta que pode confundir.

Quanto à descrição das vias, as rotas sugeridas diferenciam a pista principal da BR-101 (Salgado Filho) da pista marginal. Na navegação por texto e voz apenas o ponto nodal retorno foi informado pelo aplicativo.

Ambas as rotas sugeridas pelo aplicativo seguem pelo viaduto, mas não há informação na navegação por texto e voz sobre esse ponto nodal. O Waze exibe no mapa a informação "Viaduto acesso Marg. Av. Senador Salgado Filho" e informa por texto e voz sobre o acesso à avenida Lima e Silva porém orienta para manter à direita, ocorre que, nesse ponto, pé da rampa de subida do viaduto, há uma saída à direita, o que pode confundir os motoristas.

\subsubsection{Google Maps e Waze}

Ao verificarmos a ocorrência entre as rotas dos entrevistados e as dos aplicativos, constatamos que as três principais rotas dos entrevistados encontram recorrência nos aplicativos, sendo que a rota pela Prudente de Morais tem 100\% de recorrência, ou seja, ocorre entre os entrevistados e nos dois aplicativos.

A rota mais presente nos mapas mentais (Salgado Filho - Alexandrino de Alencar) não foi a primeira opção dos aplicativos, e, no caso do Waze, ela nem foi calculada. No caso do Google Maps, ele preferiu uma rota menos extensa como primeira opção, lembrando que essa rota menor orienta o motorista a fazer uma conversão proibida.

A segunda rota com maior frequência nos mapas mentais foi a rota pela Prudente de Morais. Nos aplicativos, ela foi a primeira opção do Waze e a segunda do Google Maps. 


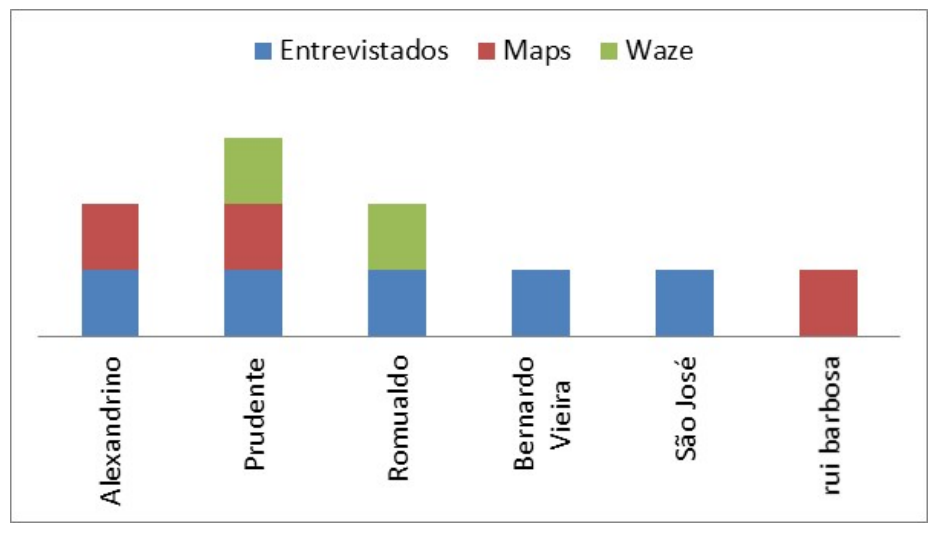

Gráfico 7 - Rotas dos entrevistados x Google Maps x Waze.

Os marcos presentes nos mapas mentais dos entrevistados não foram informados na navegação por texto e voz dos aplicativos. No mapa do Waze foram exibidos os mesmos marcos exibidos no Google Maps.

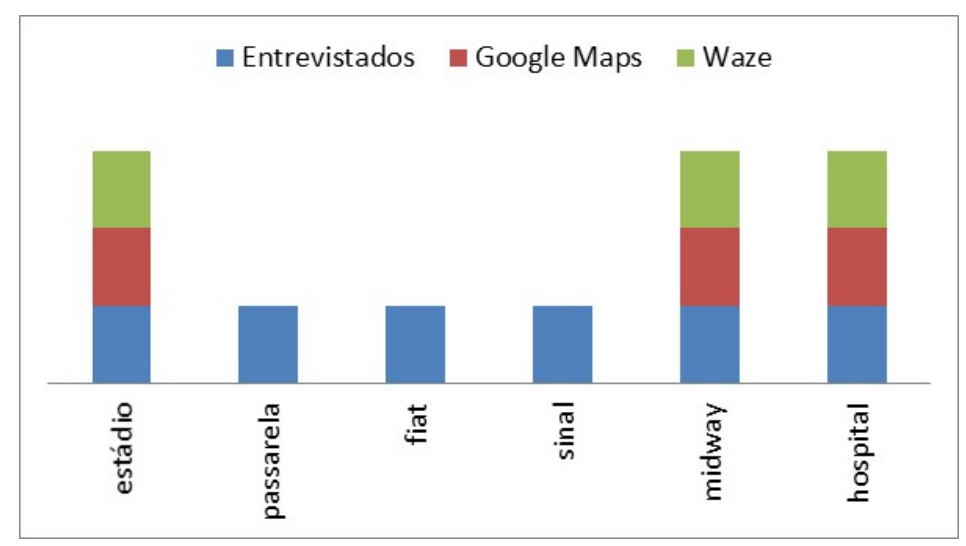

\section{Gráfico 8 - Marcos presentes nos mapas dos entrevistados x Google Maps x Waze.}

\section{CONCLUSÃO}

Os dados coletados e processados corroboraram com o trabalho de Lynch (1997) ao percebermos que os entrevistados citam os elementos vias, pontos nodais e marcos como elementos de orientação nos seus mapas mentais.

Nossa pesquisa reconhece a importância desses elementos estarem contidos nos aplicativos de recomendação de rota, corroborando também com o trabalho de Reis (2010), já que os entrevistados declararam usar a tecnologia GPS quando está procurando um local desconhecido.

A análise dos aplicativos de recomendação de rota concluiu que eles ainda não contemplam em sua totalidade os elementos de Lynch. Os aplicativos analisados contemplam apenas as vias e, de modo parcial, os pontos nodais. A ausência de marcos durante a navegação seria prejudicial aos entrevistados que declararam usar pontos de referência quando estão procurando um local desconhecido.

Também concluímos que as rotas recomendadas pelos aplicativos coincidem parcialmente com as rotas presentes nos mapas cognitivos dos usuários. O fato da rota mais traçada pelos usuários não corresponder à primeira rota recomendada pelos aplicativos se deve, em primeiro lugar, ao fato dos aplicativos recomendarem prioritariamente as menores rotas e, em segundo lugar, ao fato dos entrevistados tenderem a descrever rotas mais simples de percorrer e de explicar. 


\section{REFERÊNCIAS BIBLIOGRÁFICAS}

ALM, H. Drivers cognitive models of routes. DRIVE project V1041 (GIDS). Groningen, The Netherlands: University of Groningen, Traffic Research Centre, 1990.

ANDRADE, Isabela Fernandes; BINS ELY, Vera Helena Moro. Orientação espacial em terminal aeroportuário: diferentes perspectivas. III Encontro da Associação Nacional de Pesquisa e Pósgraduação em Arquitetura e Urbanismo arquitetura, cidade e projeto: uma construção coletiva São Paulo, 2014.

BURNETT, G. E. "Turn right at the King's Head": Drivers' requirements for route guidance information. PhD Thesis, Loughborough University, UK, 1998.

CASTRO, M. F.; TEDESCO, P. Aplicação de Conceitos de Wayfinding em Interfaces Mobile de Recomendação de Rota. In: Trilhas Técnicas. Recife, 2014.

LAKATOS, E. M. Fundamentos de Metodologia Científica. 5. ed., São Paulo: Atlas, 2003.

LYNCH, K. A imagem da Cidade. São Paulo: Martins Fontes, 1997.

NORMAN, A. Donald. O Design do Dia-a-Dia. Rio de Janeiro RJ: Rocco, 2006.

PADOVANI, S.; MOURA, D. Navegação em Hipermídia: uma abordagem centrada no usuário. Rio de Janeiro: Ciência Moderna, 2008.

REIS, Y. C. Seleção de Informação de Guia de Rota para a Concepção de Sistemas de Navegação Dissertação (mestrado) - Universidade Estadual Paulista, Faculdade de Ciências e Tecnologia - Presidente Prudente, 2010.

SCARIOT, C. A. Avaliação de sistemas de informação para wayfinding: um estudo comparativo entre academia e mercado em Curitiba. Curitiba, 2013. Disponível em: <http://goo.gl/awZQNO>. Acesso em: 24 nov. 2014. 